\title{
A Comparison Study of Sino-American Parenting Education from the Perspective of Hofstede's Cultural Dimensions
}

\author{
Xiaqing Liu ${ }^{1,2} \mathrm{a}^{*}$, Mingyun Chi ${ }^{1, \mathrm{~b}}$ and Xiaohui Dun ${ }^{1, \mathrm{c}}$ \\ ${ }^{1}$ College of Foreign Studies, Shandong Technology and Business University, Yantai, Shandong, \\ China 264000 \\ ${ }^{2}$ School of Economics and Management, Nanjing University of Aeronautics and Astronautics, \\ Nanjing, Jiangsu, China 210016

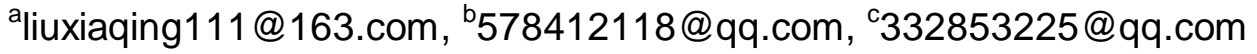

Keywords: Parenting education; Hofstede's cultural dimensions; Sino-American; Parenting style

\begin{abstract}
Parenting education is an indispensable part for the education. Parenting education reflects the value and culture. This paper first explores the relationship between culture and parenting education and divides parenting into four dimensions, namely, harsh parenting, tiger parenting, easy-going parenting, and supportive parenting whose characteristics are discussed in details. Then measurements of education are discussed and there are five first-layer measurements and fifteen second-layer measurements. Finally, differences and diversification of Sino-American parenting education are discussed in accordance with Hofstede's cultural dimensions.
\end{abstract}

\section{Introduction}

Education is composed of parenting education, school education and social education, among which parenting education is the earliest form of education and plays a crucial role in the career development of a child. Parenting education is a miniature of culture. Influenced by Confucianism philosophy, Chinese parenting is often portrayed as strict and controlling. The publication of "Battle Hymn of Tiger Mother" in 2011 put Chinese parenting education into the spotlight and inspired a hot debate over the superiority of Chinses parenting pattern. This paper reviews literature about culture and parenting, identifies the similarities and differences of Sino-American parenting education on the basis of measurement indexes, and analyses the causes for the differences from the perspective of Hofstede's five cultural dimensions.

\section{Culture and Parenting}

The culture and social environments determine the goals and beliefs of parenting education and parenting patterns, which will further influence practical parenting behaviors and parenting results (Rubin \& Chung, 2006). Consequently, parenting education varies from culture to culture in the forms of concepts, goals, methods, patterns, and results (Bornstein \& Cote, 2006).

No matter what culture they belong to, parents always do what they think best for their children. Parenting education is conducted either positively or negatively or both, which is closely related to the culture. Parenting can be conceptualized into parenting profiles in accordance with positive and negative dimensions (Kim, Wang, Orozco-Lapray, Shen, \& Murtuza, 2013), as is shown in the following coordinate.

As is shown in Fig. 1, if parenting tends to get high negative scores and low positive scores, it is harsh parenting profile or authoritarian parenting, in which parents have coercive power and the parent-child relationship is inclined to be hierarchical. If parenting tends to get high positive scores and low negative scores, it belongs to supportive parenting or authoritative parenting, in which parents are open-minded and accept reasoning. If parenting tends to get both high negative and positive scores, it is called tiger parenting, which combines authoritative and authoritarian together. If parenting tends to get both low negative and positive scores, it is named after easy-going parenting, negligent or permissive parenting. Chinese parenting, owing to Chinese salient cultural factors, is regarded as of tiger parenting (Chan, 
Bowes, \& Wyver, 2009). The parenting in America which is characterized as independence, individualism, and confidence, tends to belong to authoritative or permissive parenting (Rubin \& Chung, 2006). The parenting profile based on culture gives us a general picture about parenting in China and America and the following parts will show in detail.

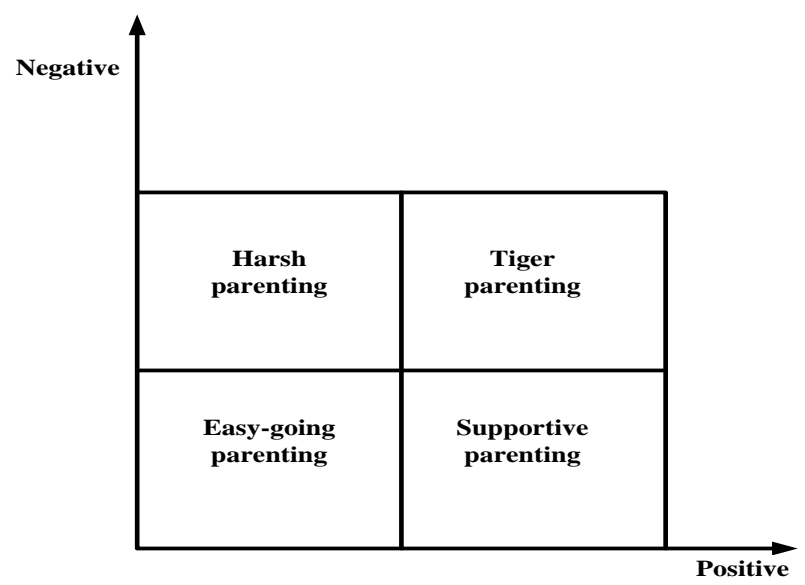

Figure 1. Parenting profile coordinate

\section{Sino-American Parenting Education Comparison}

There are similarities and differences between Sino-American parenting education. Similarities lie in three parts: Firstly, essence of parenting education. Parenting education in both countries are conducive to the mutual understanding, mutual trust and self-improvement and parents tend to educate and guide the offspring to realize independent survival for the sake of children's bright future. Secondly, the content parenting education. Parents from both countries cultivate good habits, abide by laws, show integrity, and to be friendly, honest, brave, responsible, loyal and environment-friendly, and so on. Thirdly, the forms of parenting education. Parenting education in both countries are in the form of moral education and intelligent education.

As for the differences, there are mainly six aspects. Chinese parents prefer high academic records and interdependence with other group members, and Americans emphasizes on independence. Chinese parents are proud of talents of their children while American cultivate the children in a more comprehensive way, to be social person. A survey shows that American children under 6 years old do housework for 4 hours a week, which is 5-6 times what Chinese children do. Teaching method is quite different. In China, we believe that practice makes perfect. Diligence can make up for lack of intelligence. In America, they adopt interest or hobby-oriented way. Parent-children relationship is authoritative versus democratic. The results of Chinese parenting tend to be academic achievement, for Americans creativity. At last, the assessment is different, Chinese parents always do the horizontal comparison. They compare their children with the No.1 student in the school, with the children of friends, relatives, and neighbors. American parents prefer to compare in vertical way, are their children making progress or draw back.

As for the reasons, there are mainly five contributive factors. They are economic factor, historical factor, different Values of Success, different values of life and different values of thinking. Firstly, China endures a long history of feudal society, and they are used to be obedient, and conservative. American had the War of Independence, Westward Movement, and tend to be innovative, risk-taking. Secondly, American has better medical security, and pension security. As Chinese old saying goes "A young idler, an old beggar". They should be hard working for their security of old age. Another Chinese old saying, "to be a scholar is to be on the top of the society", credential society, person with better education background are more likely to find a good job, and get promotion. American parents prefer to give full play to their interests and strong points to explore all their potentials. By contrast, Chinese parents choose to get scholarly honor or official rank and wining honor for family; children as the continuation of their self-worth, the whole part of life and beacon of hope. Finally, American tend to be 
self-interest and self-actualization, while Chines emphasize on affection and always put relationship or guanxi in Chinese at the first place.

\section{Parenting Education Measurement}

According to Zhang (2014), parenting education can be measured from the following five aspects: content of parenting, methods applied in child-rearing, goals of family education, parent-child relationship, and gender role and preference in child-rearing, which can be further divided into specific secondary measurements, as is shown in the following table 1. The parenting education comparison between America and China in terms of secondary measurements will be discussed in next section.

Table 1. parenting education measurement

\begin{tabular}{|c|c|c|}
\hline & Measurements & Secondary measurements \\
\hline \multirow{15}{*}{$\begin{array}{l}\text { Parenting } \\
\text { education }\end{array}$} & \multirow[t]{3}{*}{ Contents of parenting } & Toilet training for children \\
\hline & & Sex education \\
\hline & & Parenting program or training class \\
\hline & \multirow{3}{*}{$\begin{array}{l}\text { Methods applied in } \\
\text { child-rearing }\end{array}$} & Control over children \\
\hline & & Assistance of grandparent childcare \\
\hline & & Opportunities created for children \\
\hline & \multirow{3}{*}{$\begin{array}{l}\text { Goals of parenting } \\
\text { education }\end{array}$} & Academic achievement \\
\hline & & Social person \\
\hline & & Personality and character development \\
\hline & \multirow[t]{3}{*}{ Parent-child relationship } & Time and space shared with children \\
\hline & & Parent authority \\
\hline & & Expectation of reward from children \\
\hline & \multirow{3}{*}{$\begin{array}{l}\text { Gender role } \\
\text { preference } \\
\text { child-rearing }\end{array}$} & Gender role \\
\hline & & Gender preference \\
\hline & & Number of children \\
\hline
\end{tabular}

\section{Analysis Based on Hofstede's Five Culture Dimensions}

Despite similarities of parenting education between China and America which lies in the attitudes towards mastery of a skill, family rules, number of children, and favored children's characters, Chinese and American parenting has various differences, which can be explained from Hofstede's five classical culture dimensions (Zhang, 2014). The cultural dimensions were proposed based on a series of empirical researches and studies which covered over 110,000 employees from more than 70 IBM subsidiaries across 40 countries, namely, individualism vs. collectivism, masculinity vs. femininity, power distance, uncertainty avoidance, and long term orientation vs. short term orientation (Hofstede, 2008).

Individualism vs. Collectivism. In accordance with Hofstede (2008), this dimension concerns about the extent to which a culture emphasizes on individual or group. Individualism expects that individuals are more loosely linked to groups and do things at their own will. Collectivism expects individuals to be integrated in collectives and groups and regard themselves as members of groups. China is a typical collectivistic country with a low individualism index score of 20 , while America is an individualistic country with a high individualism index score of 91 (Hofstede, 2005: 78).

As for the contents of parenting, in China, it is believed that babies are dependent on the care of parents, and parents should be responsible for everything related to their children even including going to toilet. They will conduct toileting training for their children as early as they are five or six months old. In contrast, American think that a child can defecate independently and they do not bother to train it, so it is common that a four or five-year-old American baby is still wearing paper diapers.

As for methods of parenting, firstly, in China, family members have close relations with each other. Chinese parents are wild about figuring out what their children are thinking and likely to dig over their 
children's mind from checking their diaries or emails. In comparison, American children have stronger awareness of ego and privacy protection and their parents respect it. Secondly, a large number of Chinese grandparents help take care of children, while American parents prefer to be full-time parents which can be regarded as a feature of relatively weak family tie. Moreover, Chinese parents undertake financial support obligation for their children because children are the continuation of parents' self-worth. They will try their utmost to pave the way for children's future. By contrast, American parents are more likely to cultivate children's independence and unwilling to sacrifice their own happiness for children's financial support.

As for the goals, Chinese parents pay more attention to academic achievements, which can be proven by numerous academic records of Chinese prodigies. American tend to cultivate children in a more comprehensive way, following the interests and hobbies of children.

As for parent-child relationship, Chinese parents prefer to keep children around them all day in order to take care of them. For example, it is common that Chinese children sleep with parents until they are almost ten years old. However, American children are trained to sleep alone or do things independently at early ages. In addition, Chinese parents expect that their children take care of them when they are old or weak, while American parents are inclined to refuse to burden on their children.

Masculinity vs. Femininity. This dimension refers to the degree to which a specific culture values the qualities of ambition, assertiveness, aggressiveness, competitiveness, and material success or the qualities of solidarity, friendliness, and security (Hofstede, 2008). It is often referred to as "tough and gentle" dimension. Chinese and American cultures have masculinity index scores of 84 and 63 respectively, so both belong to moderately masculine for the highest score is 317 and lowest score is -239 (Hofstede, 1991).

In terms of gender roles and preference, mothers in China involve more in childcare than fathers due to feudal labor of division. Moreover, there is a tendency for parenting role as 'strict mother, kind father', while American fathers are likely to engage in childcare. Another thing is that a boy baby is more preferred than a girl in China due to traditional feudal thought, while in America such gender preference is not so significant.

Power Distance. This dimension refers to the degree to which members with less power in a culture or an organization consider and accept the power is endowed unequally (Hofstede, 2008). In a culture with large power distance index, people are more dependent on superiors and tend to accept power disparity and diversification of social power. In contrast, people from small power distance prefer consultation and value equality of all social levels. Hofstede (2005) ranked China 12-14 with power distance index (PDI) 80 in 74 countries and regions and United States 57-59 as a country of small power distance with a relatively low PDI of 40.

Chinese parents have a lot of methods to deal with mischievous children, such as physical punishment, no-present, and confinement, to show their power in authoritative and authoritarian way. American parents can treat children as equals. Moreover, modesty and obedience are qualities preferred by Chinese parents.

Chinese children are taught to how to climb the power ladder from an early age. Scholars enjoy high social reputation and status so parents are more proud of children's academic achievements than those of other aspects. Equality is rooted in American culture, so American children can follow their interests and pursue artistic, aesthetic, fitness accomplishment as well as academic ones.

Uncertainty Avoidance. This dimension refers to the extent to which members of a culture tolerate uncertainty or ambiguity when dealing with risks (Hofstede, 2008). National Culture (n. d.) gives the explanation that countries with strong uncertainty avoidance index (UAI) are not acceptable to uncommon behavior and ideas, while weak UAI societies hold a more tolerate attitude. In accordance with Hofstede (2005), both China and United States keep low uncertainty avoidance, with relatively low uncertainty index of 40 and 46 respectively.

Sex education is often excluded from parenting education in China, for parents worry that children may go astray if they know much about sex. By contrast, American parents quite ease at discussing sex with children as an exploration of unknown world. 
Chinese parents often try best to protect their children from uncertainties and help children deal with difficult situations. On the contrary, American parents are more likely to take a 'let-it-go' attitude and let children handle situations independently.

Long Term Orientation vs. Short Term Orientation. This dimension refers to "time horizon" of a culture or attitudes towards the importance of the past, present and future. It is closely linked with the Confucian philosophy — persistence, thrift, personal stability, and respect for tradition (Hofstede, 2008). In a culture with long term orientation, people plan and prepare much about the future, so they value thrift, endurance and humility. On the other hand, in a culture with short term orientation, people pay much attention to the present, so they appreciate efficiency, effectiveness and freedom. According to Minkov \& Hofstede (2012), China enjoys high long term orientation with the index of 174, while the United States is characterized with short term orientation with a lower long term orientation index of minus 42.

It is common in China that children participate in a variety of training classes or parenting programs even from kindergarten, which make preparation for the future. Comparatively, American parents think highly of childhood leisure time which is regarded as a precious fortune.

It has been mentioned above that Chinese parents expect to be looked after by their children, while American rarely expect in that way. Apart from the reason of individualism and collectivism, the long term orientation is a reason as well. Chinese parents look forward to return and reward from their children.

\section{Conclusions}

Parenting education is inseparable with culture. Generally speaking, Chinese parenting tends to be a tiger parenting, while American parenting is likely to be supportive or easy-going parenting. Parenting education can be discussed from 5 first-level measurements which in turn are divided into 15 second-level specific aspects. Apart from similarities, the differences between Sino-America parenting education can be analyzed with the help of Hofstede's five cultural dimensions, and reflect cultural differences in turn.

\section{Acknowledgements}

This paper is sponsored by Teaching Reform Project of Shandong Technology and Business University (No. 11688JXYJ2015009) and 2016 Blended Learning Teaching Curriculum Reform Project of Shandong Technology and Business University.

\section{References}

[1] G. Hofstede, Cultures and Organizations: Software of the Mind, McGraw-Hill, London, 1991.

[2] G. Hofstede, G. J. Hofstede, Cultures and organizations: Software of the Mind (Revised and expanded 2nd ed.), McGraw-Hill, New York, 2005.

[3] G. Hofstede, Culture's Consequences: Comparing Values, Behaviors, Institutions and Organizations across Nations. 2nd Edition, Shanghai Foreign Language Education Press, Shanghai, 2008.

[4] K. H. Rubin, O. B. Chung, Parenting Beliefs, Behaviors, and Parent-child Relations, Psychology Press, New York, 2006.

[5] M. H. Bornstein, L. R. Cote, Parenting cognitions and practices in the acculturative processes, in: M. H. Bornstein, L. R. Cote, (eds.) Acculturation and Parent-Child Relationships: Measurement and Development, Lawrence Erlbaum Associates, Mahwah, 2006, pp. 173-196.

[6] M. Minkov, G. Hofstede, Cross-cultural Analysis: The science and art of comparing the word's modern societies and their cultures, SAGE Publications, Inc., California, 2012. 
[7] National Culture (n.d.) [online] Available: https://www.geert-hofstede.com/national-culture.html [Accessed: 28 November 2016]

[8] S. M. Chan, J. Bowes, S. Wyver, Chinese parenting in Hong Kong: Links among goals, beliefs and styles. Early Child Development and Care, 179 (2009), pp. 849-862.

[9] S. Y. Kim, Y. Wang, D. Orozco-Lapray, Y. Shen, M. Murtuza, Does 'tiger parenting' exist? Parenting profiles of Chinese Americans and adolescent developmental outcomes. Asian American Journal of Psychology, 4 (2013), pp. 7-18.

[10] W. Zhang, A comparison research parenting between China and the United States from the perspective of culture dimensions. M. Ed. Dissertation, Southwest Petroleum University. 